outward, until the os is quite without the vulva. twice supervened and ran a normal course. MackenWith a scalpel the anterior vaginal wall is then split rodt mentions one normal pregnancy in his cases. It from a point one-third to one-half an inch beneath is quite probable that this operation, like all other the urethral opening down to the portio vaginalis. new operations, will be illy done and overdone. As The mucous membrane is carefully dissected off from a result we shall have much conflicting testimony as the submucous tissue for some distance on either side to its value.

of the incision, the submucous tissue shoved up and its bleeding vessels stilled by several stitches of continued catgut suture. This maneuver leaves the uterine wall bare for the distance of one or two centimeters above the internal os. The vaginal wall is now united directly to that of the uterus by means of three strong silk sutures, the first of which passes through the uterine wall about three-fourths of an inch above the internal os, the second at the internal os, and the third about the middle of the uterine neck. Super-

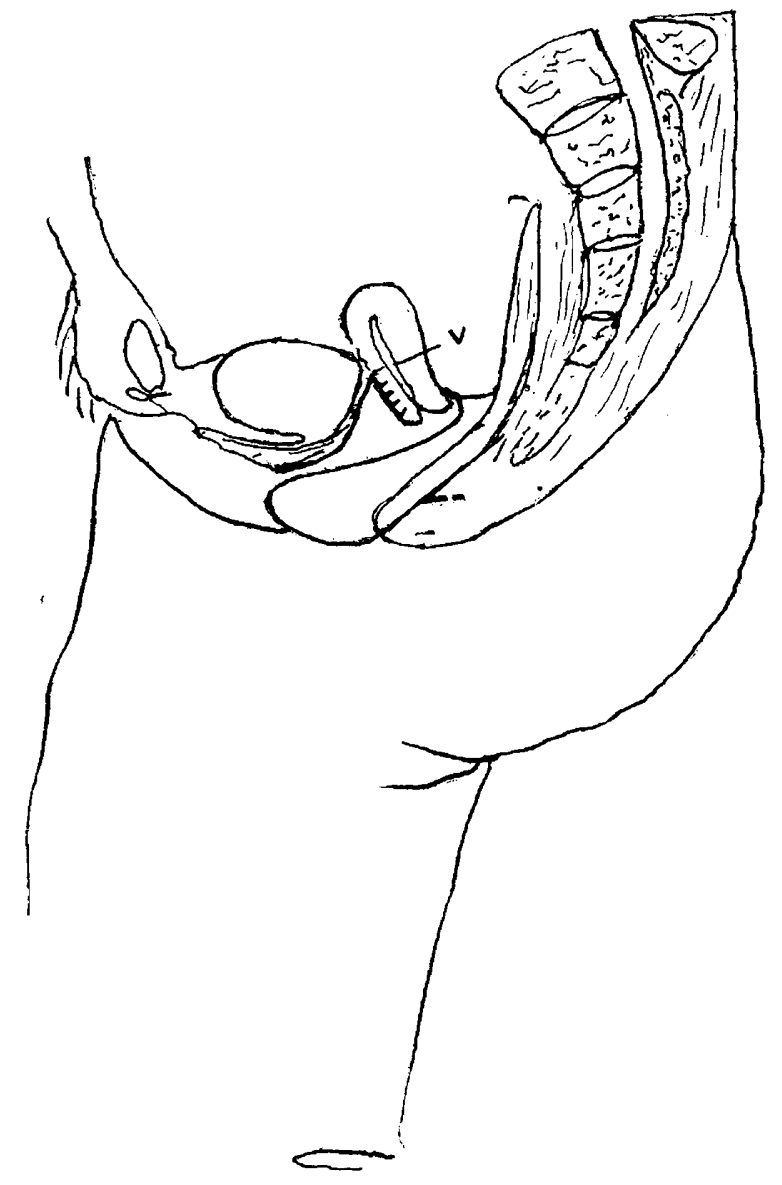

Fig. 7.-Mackenrodt's operation. Sectional view. V, anterior vag. fnal wall bent upon itself and secured to uterus. Upper part of vagina distended.

ficial catgut sutures close the spaces between the silk sutures. The silk sutures are allowed to remain in situ three months. There is no doubt a possibility of injuring the bladder in performing this operation. The injury may be either direct or through subsequent inflammation of the tissue between the uterus and the bladder. I saw in Landau's Clinic, in Berlin, one such case. There was extreme sensitiveness and other evidences of vesical inflammation. The patient had been operated upon by Dr. Vogel several months before.

The operation is new and therefore its value is unknown. Martin has great hopes of its efficiency and says he has had no complications following it. In turns upon the significance of the word reaction. The the first thirty of his cases pregnancy afterwardslexpression, irritation or injury, conveys a clearer im- 
pression to the mind, and bacteria become linked with the subject at this point. The reaction process belongs to living cells and may be divided into a defensive and constructive stage. The latter might not be called inflammatory in a strict sense of the word. However, the end and aim of the defensive process is to arrive finally at the constructive. In a given wound there may be much or little to defend but the leucocytes are poured out notwithstanding; if not needed for defense they proceed immediately to construction. Defense and construction are supplementary in a process which aims ultimately at restoration. In both steps the same elements, leucocytes and phagocytes play their parts.

So far as defense is concerned, phagocytosis is the most active and striking phemomenon. It is observed in the lowest and slightly differentiated forms of life, as well as in the highest. Comparative study shows that phagocytosis is less active in man than in the lower animals. A high degree of tissue differentiation evidently makes phagocytes less numerous or renders them less effective. This is perhaps one of the sacrifices the human and other highly differentiated species have to make for the advantages of possessing highly specialized tissues.

The next step in the defensive process differs from phagocytosis, inasmuch as it is only seen and studied in the more highly organized forms of animal life. It is in fact a concerted activity, a combination of forces whereby millions of phagocytes and leucocytes do through organization what a single one would do in simple phagocytosis. Instead of one by one englobing bacteria, they by concerted process surround the lot. Thus we get the so-called circumscribing action or union of forces with one intent. By it the contest is made to take place within boun. daries. This circumscription is in fact a measure of last resort, simple phagocytosis having failed. The end to be attained here is the formation of an abscess. The inflammatory products and irritant materials are hemmed in by the so-called pyogenic membrane or wall extemporized for the purpose of limitation. The very natural result of this confinement is the production of those classical symptoms of inflamma. tion, pain, heat, redness, swelling, and loss of function. These symptoms appear more or less prominently according to the results of the defensive process. The contents of an abscess consist of serum, leucocytes, phagocytes, bacteria and chemic toxins with possibly some fibrin and tissue débris. Clinically this material is known as pus. In the formation of the typical abscess, the aim is one of limitation. An abscess is in a measure destructive, but the damage is confined, and thus the sacrifice of a part is made often for the benefit of the whole organism. The circumscribing action is less necessary on surfaces; it does at times occur and is then marked by a barrier of deep induration.

The defensive process has been seen to consist in a phagocytosis and a circumscribing action, but the same call which summoned the leucocytes to the defensive, leaves them upon the site of injury for the purpose of reconstruction. Defensive and constructive activity seldom go hand in hand; they follow one another, but the way must always be cleared before repair can begin. Construction takes place also with the help of the fixed connective tissue cells and it occurs promptly, providing the energy of the tissue cells has not been entirely exhausted in the defensive struggle. Construction implies organiza tion or regeneration. It has been stated that special. ization or the higher evolution of the tissues of an organism was accompanied by a diminution of phagocytic activity, so the same higher development entails a feebleness in the regenerative or reconstructive function.

We have therefore to consider the human organism as having purchased its higher development at some considerable cost, it being in consequence provided with less active phagocytes for defense and less active leucocytes for construction. In the lower animal kingdom the regenerative function is so active that not only are injured organs successfully repaired, but lost limbs and processes are reconstructed. A lobster having lost his claw can grow a new one. The tadpole may regenerate a lost tail, etc. In man, mesoblastic or connective tissue almost monopolizes the regenerative function. It is the one tissue that has suffered the least differentiation. Phagocytes and leucocytes are derived from it, and are very largely the agents through which it works. In man a wound or loss of substance of the liver or brain is replaced by fibrous or mesoblastic tissue; the liver or brain cells are too much specialized to be capable of self repair. Observation on all the other tissues of the human body shows a striking feebleness in this regenerative capacity.

Having defined inflammation as a reaction which arose from an irritation or injury, we have now to in. vestigate this irritation. Primarily we can conceive of irritation or injury only as arising from mechanical, chemical or thermal causes. Considering chemical causes only, these may operate directly or indirectly. When directly, it can be proved that inflammation may arise through, for example the application or injection into living tissues of some chemic irritant, germ free. This process is chiefly one of experimental interest. The mode of introducing a chemic toxin indirectly into the tissues through the agency of bacteria has the widest clinical significance. The direct mode is often mis. leading, for the direct use of any chemic irritant creates in living tissue a locus minoris resistentix and may thus ultimately induce bacterial invasion. The direct method should, however, have nothing to do with bacteria, though it would be a purely chemic matter whether we injected aseptically into living tissues croton oil, turpentine or phlogosine, an alkaloidal product of certain pyogenic organisms. If these substances are used we get substantially the same result as in microbic inflammation, though without microbes we miss their peptonizing action which yields the typical fluid pus, while that called forth by chemic irritants is more or less coagulated and semi-solid. It has been called puruloid by some writers.

Clinically, bacteria acting as agents for the generation of toxic and irritant material, are by far the most frequent causes for inflammation. Their products are the acting or exciting causes and these are usually alkaloidal or belong to that class known as albumoses or toxalbumens. Hence they fulfill the idea that the irritant must be a chemic one. The mechanical influences of bacteria were at first given considerable prominence, but later and more careful investigation, has shown this to be too inconsiderable to notice. Even in so severe a disease as septicemia, mechanical effects account for nothing. 
And again the idea that bacteria simply deprive the tissue cells of their accustomed oxygen and food has been shown to be of altogether minor importance. The action of certain bacteria for harm is an aggressive and strictly positive one.

In certain forms of chronic inflammation, as for example, the interstitial inflammation of solid organs like the kidneys, liver, spinal cord, etc., there exists an overgrowth of the connective tissue framework. There may at first be hypertrophy of the whole organ as is often the case in the early stage of chronic interstitial hepatitis. This is soon followed by an atrophy and degeneration of the functional cells, which advancing more rapidly than the formative process in the framework leave the organ finally much contracted. Contracted, moreover, because of the property of the new-formed connective tissue to shrink after the manner noticed in cicatrices. Such conditions as these, if they are rightly called inflammatory, and it would seem best to call them so, are brought about usually by some chemic irritant whose influence is exerted upon the tissues during a long period of time. Such chemic subetances usually act directly upon the living cells. They may be the products of some recent bacterial invasion like diphtheria or more remotely sy philis. Again, they may have nothing to do with microbes, and be the products of the living tissue itself, e.g., uric acid in the lithemic or bile in the cholemic conditions. Finally, it is seen that substances derived from without are equally capable of producing interstitial change, $e . g .$, the prolonged use of alcohol and the effects of chronic lead poisoning.

The influeuce of these irritants are in the above instances just enough to provoke connective tissue proliferation, while they damage the more highly specialized or functional cells of an organ.

Once more it is seen that higher organization has its disadvantages, in that it ultimately gives rise to celis whose resistance to detrimental agencies are inversely proportioned to their degree of evolution or specialization. A highly specialized cell does better work than one less evolved, but as a compensation it needs greater protection, for it succumbs very readily to harm and there is left little or no prospect of restoration.

We know of large numbers of pathogenic bacteria but they do not all excite inflammation. Inflammation is in many cases a protest on the part of tissues against the toxins of an invading organism. Unfortunately, perhaps, there are some bacteria and toxins that provoke no tissue protest. It is well known that there are many toxic alkaloids that create no inflammatory reaction; $e . g$. aconite, strychnin, morphin, atropin, etc. The toxins of hydrophobia and tetanus call forth little or no defensive action on the part of the tissues. Very susceptible animals may offer little or no inflammatory reaction to anthrax; thus in man we have occasionally acute miliary tuberculosis. Both illustrate conditions where there is no local protest or circumscribing action, but as a consequence a quick, general, systemic invasion. The insidious character of an infection without distinct local inflammatory manifestations is often seen in syphilis. The local lesion being occasionally too trifling to notice. Man, for example, is not very easily infected with anthrax, hence we expect a vigorous local reaction, and this is usually the case in malignant pustule.
Infection may take place with or without resistance, but inflammation never occurs unless resistance is offered. As tissues approach death their inflammatory vigor diminishes at an equal rate. In all inflammation, antagonism is necessary. Cell antagonism is most typically exhibited toward living microbes, and less toward toxins and chemic irritants.

\section{THE CENTRIFUGAL MACHINE IN SPUTUM EXAMINATIONS.}

\section{BY WALTER G. HUDSON, M.D.}

BACTEKIOLOGIST TO NORTHEASTERN IISPENSARY; MEMBEK NEW YOHK PATHOLOGICAI, WOCIETY, HARLEM MEDICAL ASSOCIATION, ETC.

Owing to its precision, the diagnostic aid given by a microscopic examination for tubercle bacilli of the properly stained sputum has made this procedure very popular. The only difficulty lies in the fact that, by the old methods of examination, we may sometimes unconsciously select a portion of the sputum that contains no tubercle bacilli, if the entire specimen contains but few.

To eliminate this source of error, I have of late been using with much satisfaction the method advocated by Biedert, employing in addition the centrifugal machine. Where possible, I secure all the sputum raised in twenty-four hours, and add some potassium hydrate solution; this, with the aid of heat, dissolves any lumps that may be present and after a time the mixture becomes quite thin. It is then diluted with water so as to lower the specific gravity, and introduced into a large centrifugal machine. The latter is then run at a high speed for a half hour, which throws down all solid particles, bacteria included; and the specimen to be examined is then taken, by means of a pipette, from the bottom of the conical part of the tube.

I report the following case to show the usefulness of this method:

About a year ago I saw, with a colleague, a dispen. sary patient of his, Miss M. F., aged 18, who had been suffering for some time with a cough, with slight watery expectoration. At times she had sweats which were not profuse and did not occur often. Temperature 99 ; pulse 92 ; tongue coated white. She was anemic, but not emaciated. Both parents were living. She had originally come for a tonic, because her friends told her she looked pale. Hap. pening into his room at the dispensary one day, my friend casually asked me what I would give, as she had not improved under treatment.

Upon hearing the history, I asked for and received permission to examine her chest. The only abuormal physical signs were on the right side where there were some mucous râles, and near the apex I heard a slight pleuritic friction sound, but it was so slight I did not succeed in convincing my friend it was there. The girl admitted that she sometimes had pain in that region, "muscular rheumatism," she called it. Neither of us could detect any consolidation.

Dr. - was positive that there was nothing tubercular about the case, as he had examined the sputum himself. However, as we were both greatly interested in the subject of tuberculosis, he secured another (morning) sample of sputum, and we examined it together at my laboratory. Out of eight slides examined, we found two tubercle bacilli, both of which were in the second preparation. Dr.__ insisted that these might be an accidental contamination from 